\title{
Gas Drainage Technology in Fully Mechanized Caving Face with Horizontal Sublevel Mining in Steep and Extra-Thick Coal Seam
}

\author{
Bingxing Sun ${ }^{1,2}$ \\ ${ }^{1}$ National Key Laboratory of Gas Disaster Detecting, Preventing and Emergency Controlling, Chongqing, China \\ ${ }^{2}$ China Coal Technology and Engineering Group, Chongqing Research Institute, Chongqing, China \\ Email: sunbingxing@163.com
}

How to cite this paper: Sun, B.X. (2020) Gas Drainage Technology in Fully Mechanized Caving Face with Horizontal Sublevel Mining in Steep and Extra-Thick Coal Seam. Open Journal of Geology, 10, 957-970. https://doi.org/10.4236/ojg.2020.109043

Received: July 31, 2020

Accepted: September 26, 2020

Published: September 29, 2020

Copyright ( 2020 by author(s) and Scientific Research Publishing Inc. This work is licensed under the Creative Commons Attribution International License (CC BY 4.0).

http://creativecommons.org/licenses/by/4.0/

\begin{abstract}
This paper analyzes the gas source of the horizontally sectioned fully mechanized caving face in the steeply inclined and extra-thick seam of Adaohai Coal Mine, and numerically simulates the stress distribution and pressure relief of the lower section coal after the upper section working face is mined. It theoretically analyzed the reasonable layout of the drainage boreholes, and designed the drainage borehole layout accordingly. In the upper and lower section of the working face, the actual drainage effect of the boreholes was inspected, and the air exhaust gas volume in the working face was statistically analyzed. It was confirmed that the layout of boreholes was reasonable, the gas control effect of working face was greatly improved and fully met the needs of safe mining. The control effect was greatly improved and the need for safe mining was fully met, and thus a gas drainage technology suitable for the coal seam storage conditions and mining technology of the Adaohai Coal Mine was found. That is to say: the gas emission from the working face of the section mining mainly comes from its lower coal body. Pre-draining the lower coal body of the section and depressurizing gas interception and drainage are the key to effectively solve the problem of gas emission from the working face. Drainage boreholes in the working face of the section should be arranged at high and low positions. The high-level boreholes are located about $2 \mathrm{~m}$ from the top of the working face, and the high-level boreholes are about $9 \mathrm{~m}$ away from the top of the working face. Through the pre drainage of high and low-level boreholes in advance and the interception and pressure relief drainage, the gas control in the horizontal sublevel fully mechanized caving mining face in steep and extra thick coal seam can realize a virtuous cycle.
\end{abstract}

\section{Keywords}

Steeply Inclined Extra Thick Seam, Horizontal Segmentation, Top Coal 
Caving, The Source of the Gas, Pressure Relief Gas Drainage

\section{Preface}

In the western and southern areas of China, $80 \%$ of the mining areas have steeply inclined coal seams, and $20 \%-30 \%$ of the mining areas in the north and northeast have steeply inclined coal seams [1] [2] [3]. China is the enrichment area of steeply inclined extra-thick coal seam, and its coal seam reserves account for more than $30 \%$ of the similar coal seam reserves in the world [4]. The occurrence of steeply inclined extra-thick coal seam is complex and the mining is difficult. At present, the common mining method is horizontal sublevel caving. Due to the characteristics of horizontal sub-level fully mechanized top-coal caving face in steeply inclined super-thick coal seam, such as large mining and caving ratio, difficult control of top-coal, self-unloading gas desorption and migration of bottom coal body, more coal remaining in Goaf, etc., as a result, the work of gas prevention and control in working face is more difficult. With the further exploration and development of coal resources, more and more steeply inclined thick coal seams will be mined in the future, the gas disaster will also become the main difficult problem [5]. The gas occurrence law of steeply inclined super-thick coal seam is different from that of gently inclined coal seam [6]. The gas emission law and form are also different from that of gently inclined coal seam. However, the research on gas disaster control in horizontal sublevel mining of steep and extra-thick coal seam is relatively insufficient at present, and how to effectively prevent gas disaster has become the key to ensure the safety and high-efficiency production of steep and extra-thick coal seam.

Adaohai Coal Mine, located in Inner Mongolia, is a typical mine for mining steeply inclined extra-thick coal seam. Because of the uneven gas emission, in the process of fully mechanized sublevel caving mining face, the gas over-limit phenomenon often occurs at the back side of the conveyor and the return corner of the mining face, which brings the big hidden danger to the mine. In order to carry out gas control work better, it is necessary to carry out theoretical research on coal seam pressure relief, gas migration and gas emission law under horizontal sublevel caving mining in steeply inclined super thick coal seam, through analyzing the source of gas emission and optimizing the gas extraction technology, the paper puts forward the technical measures of gas extraction with pertinence, and finds a gas extraction technology suitable for the mining technical conditions of Adaohai Coal Mine, therefore, it can provide beneficial reference for gas disaster control under similar mining technology conditions.

\section{Engineering Overview}

The capacity of Adaohai Coal Mine is 900,000 t/a, and the development mode is multi-level development of central parallel inclined shaft. The mine adopts 
two-wing mining, one mining area is arranged in the east and the West, and " 1 mining, 2 excavation and 2 preparation" is adopted to organize production and achieve production. The ventilation mode of the mine is subarea ventilation, the ventilation method is extraction ventilation, the ventilation of the coal mining face is full air pressure ventilation, the air is imported from the South Lane of the working face, and the dirty air is returned to the return air lane of the mining area. The absolute gas emission is $28.9 \mathrm{~m}^{3} / \mathrm{min}$ and the relative gas is $16.9 \mathrm{~m}^{3} / \mathrm{t}$, which is high gas mine. CU2 coal seam is the main mining coal seam, the thickness of coal seam is $22-35 \mathrm{~m}$, the average thickness is $28 \mathrm{~m}$, seam dip is $80^{\circ}$ $90^{\circ}$, the gas content of CU2 coal seam is $7.35 \mathrm{~m}^{3} / \mathrm{t}$, gas content gradient is 1.65 $\mathrm{m}^{3} /(\mathrm{t} . \mathrm{hm})$, the gas pressure of coal seam is $0.85 \mathrm{Mpa}$. At present, the working face is W1091, the prepared working face is W1075 and E1101 fully mechanized caving face, and the prepared working face is E1085. The working face parameters are basically the same, the length of the working face is $500-600 \mathrm{~m}$ (strike), the face length is $28 \mathrm{~m}$ (seam thickness), the slice thickness is $16 \mathrm{~m}$, the mining area is $2.5 \mathrm{~m}$, the mining area is $13.5 \mathrm{~m}$, and the mining area ratio is about 1:5.4.

The position relationship between upper and lower segmented working faces is shown in Figure 1.

\section{Source Analysis of Gas Emission}

The gas emission from the coal mining face depends on many factors such as natural factors of the coal seam and mining technical conditions. There are no adjacent layers on the top and bottom of the CU2 coal seam of Adaohai Coal Mine, which belongs to the mining of a single steeply inclined extra-thick coal seam. Therefore, the source of gas emission during mining at the working face is all coal seams. According to the characteristics of comprehensive mechanized coal mining and the theory of gas flow [7], since the amount of gas emission from the surrounding rock is small and negligible, the source of gas emission from the working face can be divided into the coal wall of the working face (Including cutting coal wall $\mathrm{q}_{1}$, lower coal body $\mathrm{q}_{2}$, and upper coal body $\mathrm{q}_{3}$ ) gas emission, coal falling (including mined coal $\mathrm{q}_{4}$ and caving coal $\mathrm{q}_{5}$ ) gas emission and goaf (including upper section goaf $\mathrm{q}_{6}$, this section mined area $\mathrm{q}_{7}$, the lower segment of solid coal $\mathrm{q}_{8}$ ) three parts of gas gushing, mainly shown in Figure 2.

Due to the uneven gas emission from the working face, the gas emission on the conveyor side at the back of the working face is much larger than that on the side of the coal side of the working face, resulting in excessive gas on the conveyor side at the back of the working face and the return air corner of the working face. Analyze the reasons for the above phenomenon: When caving the top coal, the gas on the side of the conveyor at the back of the mining face exceeds the limit. The main reason is that as the mining depth increases, the gas content of the coal body will gradually increase, and the coal seam gas mined at the working face has not been carried out. Effective drainage, resulting in a large amount of gas still in the coal body during the mining. When the roof is suddenly topped, a large amount of gas will inevitably burst out, causing the gas to 


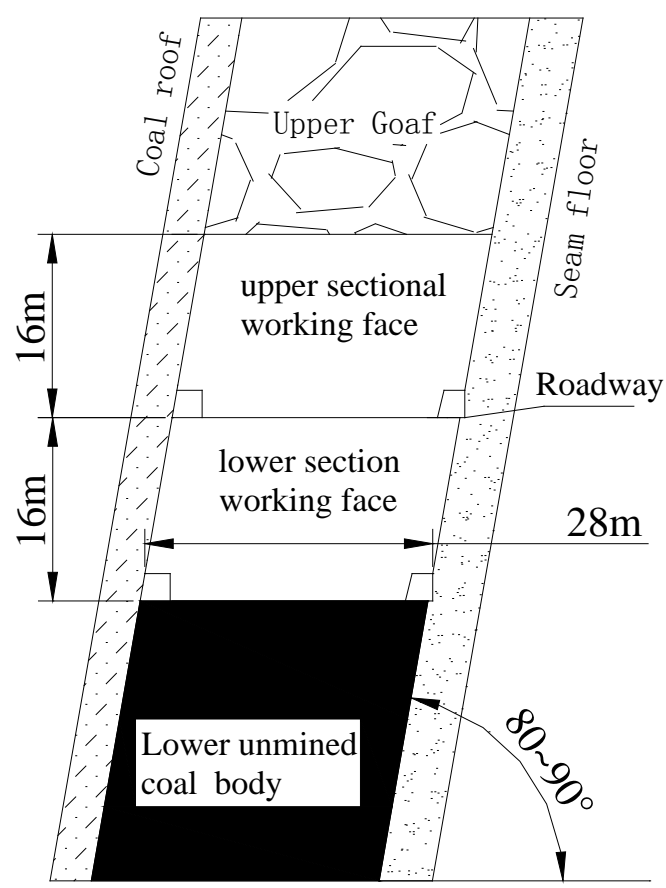

Figure 1. Relative diagram of position between upper and lower sublevel working faces.

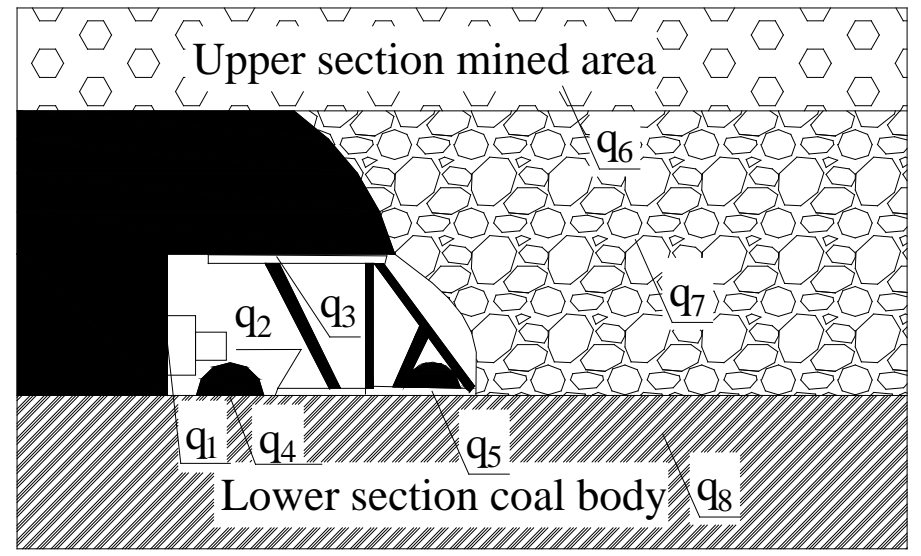

Figure 2. Schematic diagram of gas emission source in sublevel mining fully mechanized caving face.

exceed the limit on the side of the conveyor at the back of the mining face; for the corner of the working face. The reason for the excessive gas limit is that the coal under the working face is affected by mining, and a large number of cracks are generated. These cracks provide a large amount of gas stored in the coal underneath with a passage to the goaf of the working face. With the advancement of the working face, a large amount of pressure relief gas will flow into the goaf of the working face. If it is not managed in time, under the air leakage and return air corner ventilation pressure difference in the goaf, a large amount of gas will flow back to the working face. The corner of the wind and the mining space will inevitably cause the corner of the working face and the gas in the working face to exceed the limit. However, the proportion and intensity of gas emission from the 
lower coal body are still unclear, leading to greater blindness in the treatment of gas sources.

According to the source of gas emission from sublevel mining fully mechanized caving mining face, the gas emission of nine sublevel fully mechanized caving mining faces that have been mined in the Adaohai Coal Mine in recent years are counted, and the following statistical methods are used [8] [9]: 1) In the maintenance shift at the initial mining stage of the working face, the difference between the amount of gas entering and returning from the working face is the amount of gas emitted from the coal wall; 2) Before the top coal of the fully mechanized caving face collapses, the normal mining shift The difference between the gas emission from the working face and the return air is the sum of the coal gas emission from the coal face and the gas emission from the exposed coal wall. This value is subtracted from the gas emission from the exposed coal wall to obtain the coal gas Gushing amount; 3) For the coal mining shift after the first top coal pressure on the working face, calculate the gas emission from the working face, and subtract this value from the gas emission from the exposed coal wall and the gas from the coal working face, namely The amount of gas emitted from the goaf. According to statistics, $70 \%-80 \%$ of the gas emission from the working face comes from the goaf (i.e. the sum of $\mathrm{q}_{6}-\mathrm{q}_{8}$ ). The production and gas emission of 5 sub-level fully mechanized caving faces with actual measured coal seam gas content before the mining face is counted, and the "Mine Gas Emission Prediction Method" (AQ1018-2008) Considering the gas emission $\mathrm{q}_{8}$ of solid coal under the goaf of the working face, calculate the gas emission of the working face, as shown in Table 1.

The five coal faces in Table 1 only adopted the gas pre-drainage measures in this section before mining and the gas drainage before mining reached the standard. Because the lower section of the coal body within the working face is relatively less affected by mining. The wall gas emission $\mathrm{q}_{2}$ is relatively small and will not be considered in this calculation. Due to the long section mining time on the working face, the remaining coal and gas in the upper section goaf have been fully released, the gas density is low, and the gas is scattered in the upper cracks. The gas emission $\mathrm{q}_{6}$ from the goaf to the goaf of this subsection is relatively small and can be ignored here. Therefore, it can be roughly considered that the difference in Table 1 is the gas emission $\mathrm{q}_{8}$ of the solid coal in the lower part of the goaf of the mining section. From the statistical calculation in Table 1, it can be seen that the gas emission from the pressure relief coal at the lower part of the mining section accounts for $50.3 \%-63.2 \%$ of the total gas emission from the working face, with an average of $55.3 \%$, and the proportion is increasing as the mining goes deeper. The gas content of the coal in the lower part of the mining section is in its original state before the mining section is mined, and the gas content is relatively high; the pressure relief gas emitted from the lower coal body during the mining section is the amount of gas emitted from the working face. The main body and bottom coal body pressure relief gas flow is shown in Figure 3. 
Table 1. Statistics and calculation table of gas emission from the mining face.

\begin{tabular}{ccccc}
\hline $\begin{array}{c}\text { Working face } \\
\text { name }\end{array}$ & $\begin{array}{c}\text { Average daily } \\
\text { output of working } \\
\text { face during the } \\
\text { statistical period/t }\end{array}$ & $\begin{array}{c}\text { Average gas emission } \\
\text { from working face } \\
\text { during the statistical outflow in the lower section } \\
\text { period } / \mathrm{m}^{3} \cdot \mathrm{min}^{-1}\end{array}$ & $\begin{array}{c}\text { Without considering the } \\
\text { calculated value of coal }\end{array}$ & $\begin{array}{c}\text { Percentage of } \\
\text { of } / \mathrm{m}^{3} \cdot \mathrm{min}^{-1}\end{array}$ \\
\hline W1139 & 2500 & 11.9 & 5.92 & 50.25 \\
W1123 & 2600 & 12.6 & 6.16 & 51.11 \\
W1107 & 2700 & 14.2 & 5.23 & 63.17 \\
E1133 & 2600 & 13.4 & 5.93 & 55.75 \\
E1117 & 2600 & 13.8 & 6.04 & 56.23 \\
\hline
\end{tabular}

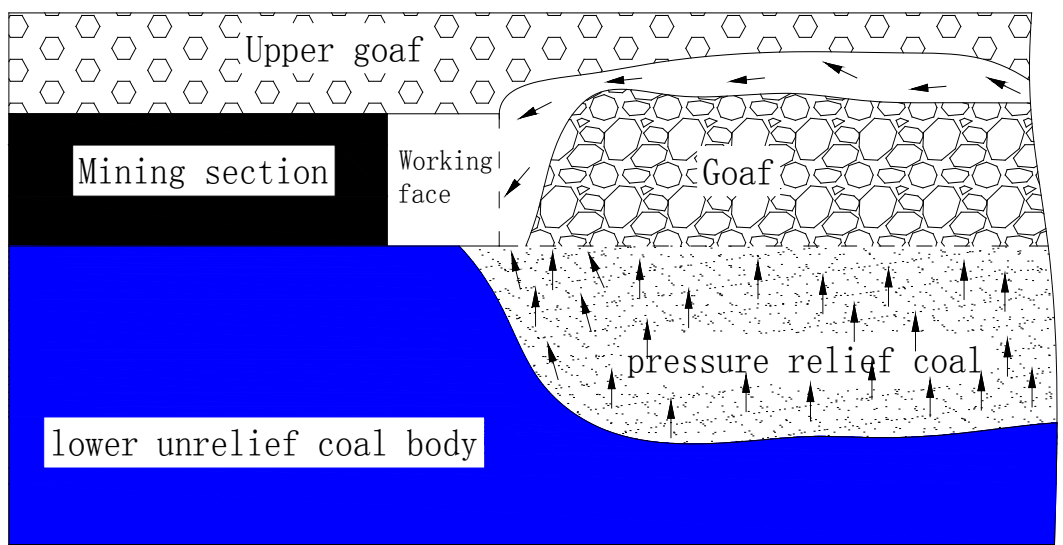

Figure 3. Schematic diagram of pressure relief gas flow in the lower coal body of the mining section.

From the above analysis, it can be seen that the fundamental measure for gas control in a fully-mechanized caving face with horizontally sectioned mining in steeply inclined and extra-thick coal seams should be pre-drainage and pressure-relief gas interception and extraction from the lower coal body of the mining section. It is the key to solve the problem of gas emission from working face in horizontal section mining.

\section{Numerical Analysis of Coal and Rock Deformation in Sublevel Mining}

In many engineering technical fields, numerical simulation software can be used to obtain numerical solutions or changing trends and laws that meet engineering needs, solve structural and mechanical analysis problems in engineering, and shorten the design inspection period and reduce engineering costs [10]. In order to study the pressure relief deformation of the coal near the roof of the lower slicing working face after the mining of the upper slicing face, and to provide a basis for the layout of the drainage drilling in the lower slicing face, the E1101 spare working face and its lower section E1085 are used The working face is a model, and numerical simulation is used for analysis and research, which provides a basis for the design of the bottom coal body pressure relief gas intercep- 
tion and drainage borehole design.

The FLAC ${ }^{3 \mathrm{D}}$ software is used for numerical simulation this time. The Mohr-Column criterion is used as the coal rock failure criterion. The numerical simulation of each coal rock is based on the actual thickness, its density, shear modulus, bulk modulus, cohesion, internal friction angle and the physical and mechanical parameters such as tensile strength are assigned according to relevant data or experience and reference manuals and considering the actual situation, and three-dimensional geometric models are established respectively. According to engineering practice, the $\mathrm{x}$-axis direction of this numerical model is the coal seam inclination, the width is $300 \mathrm{~m}$, the $\mathrm{y}$-axis is the coal seam axis, and the length is $600 \mathrm{~m}$; the $\mathrm{z}$-axis direction is the vertical direction, i.e. the direction of gravity, the height is $300 \mathrm{~m}$; the coal seam inclination angle is $80^{\circ}$. The model is divided into 411,000 units and 429,328 nodes. The model cuts the cut from $y=50 \mathrm{~m}$, the length of the working face is $28 \mathrm{~m}$, the height of mining is 16 $\mathrm{m}$ at one time, the length of mining at each time is $5 \mathrm{~m}$, and the mining is $300 \mathrm{~m}$. The mechanical parameters are selected based on the mine lithology based on experience, and $0.85 \mathrm{MPa}$ gas pressure is applied to the E1101 working face and the coal seam below it. According to the coal seam mining technology, the top coal caving mining at E1101 working face is simulated by excavating all the seams at one time, and the roof is managed by the all-over-fall method. Since there is a goaf above the E1101 working face, its impact on the floor of the E1085 working face is limited, so this simulation does not perform special treatment on the goaf. In addition, the upper part of the E1101 working face is a goaf, and its change and existence have little effect on the pressure relief of the E1101 working face's floor. Therefore, there is no feature construction for this goaf in this model. According to the results of engineering practice and theoretical analysis, the stress in the mining pressure relief zone will generally be reduced by about $50 \%$ [11]. Therefore, this numerical analysis analyzes the mining pressure relief range by comparing the stress distribution before and after model development. Figure 4 shows the mining stress distribution near the E1101 working face after mining.

By comparing the stress of each unit of the model, the vertical stress of the coal in the E1085 working face is $-1.76 \mathrm{MPa}$ before the coal in the E1101 working face is mined. After the coal in the E1101 working face is mined, the coal at the E1085 working face has a certain pressure relief According to the mining stress relief zone, the stress will generally be reduced by about $50 \%$, and the vertical stress relief boundary of $-0.88 \mathrm{MPa}$ is obtained, that is, within the range of $10 \mathrm{~m}$ depth of the E1101 working face bottom plate, the stress change reaches or exceeds $50 \%$. Strain is a direct reflection of the change in the stress distribution state. It can be seen from Figure 4 that the strain increase in the depth range of about $10 \mathrm{~m}$ under the bottom plate changes significantly, and the strain increase in the range of $3-4 \mathrm{~m}$ on both sides of the E1085 working face can be seen. The amount has changed significantly. The stress of the coal body under the mining section forms a pressure relief zone behind the working face. Mining cracks are 


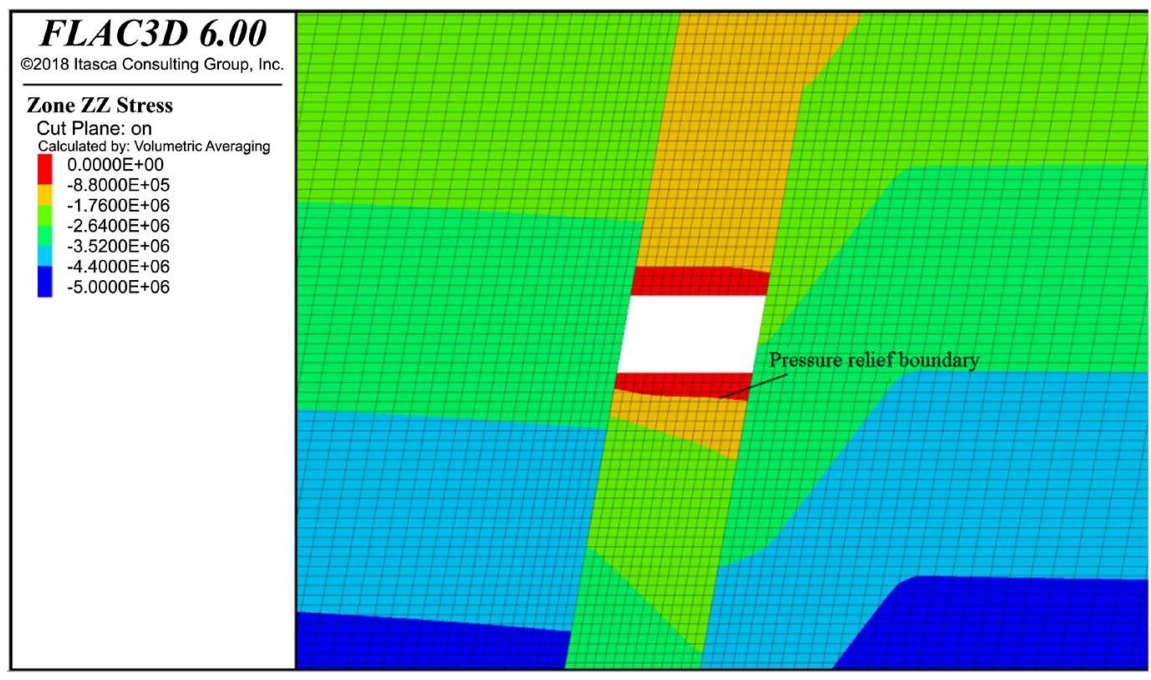

Figure 4. Vertical stress distribution cloud chart.

generated in the pressure relief zone, and the air permeability is significantly increased. The free gas contained in the coal body will follow the original cracks under the action of the pressure difference. And the mining fissures flow to the recovery space, and at the same time, due to the change of gas pressure, the adsorbed gas undergoes a process of conversion from adsorption to free, and continues to replenish free gas. As the working face advances forward, the optimal area for pressure relief gas drainage in the bottom coal body will move forward accordingly. For the interception and drainage of pressure relief gas at the bottom of steeply inclined horizontal section mining, optimizing the layout of boreholes is of great significance.

\section{Drainage Drilling Layout}

After the steeply inclined extra-thick coal seam is mined horizontally in sections, the stress of the bottom coal body increases and decreases, the coal and rock mass appear compression and expansion, and cause stretching, shear failure, and shear slippage of the layer and weak interlayer. In the pressure relief zone, the high gas contained in the coal body can be released, and the air permeability of the coal seam is increased. According to the above numerical simulation results, the mining pressure relief range of the lower part of E1085 working face after E1101 working face is within the depth of about $10 \mathrm{~m}$ under the middle of the bottom of E1101 working face, and the range of $3-4 \mathrm{~m}$ on the two sides. According to mining experience under similar conditions, it is advisable to arrange the boreholes in the lower part of the mining pressure relief range. If the boreholes are arranged on the upper part of the mining pressure relief zone, the boreholes are easily connected to the upper goaf through the pressure relief cracks; In the lower part, due to insufficient pressure relief, the pressure relief gas in the pressure relief zone coal body cannot be intercepted. Therefore, based on the current mining technical conditions of the Adaohai Coal Mine, the best final hole level for the drainage boreholes of the lower section working face should be 
arranged in the range of $2-3 \mathrm{~m}$ from the upper layer floor on both sides of the working face, and $8-11 \mathrm{~m}$ in the middle section. Within the range, it can effectively intercept the pressure relief gas that is affected by the mining of the lower section coal body after the upper section mining. Since the coal seam's horizontal section mining thickness is up to $16 \mathrm{~m}$, in order to effectively solve the gas emission of the lower section working face when the lower section working face is mined, it is very necessary to arrange a layer of low drilling holes.

Based on the above analysis, the layout plan of the drainage boreholes in the lower section working face is as follows: the drainage boreholes are arranged in the south and north lanes of the working face correspondingly to control the mining area of the section working face. The angle between the drilling azimuth and the roadway is $60^{\circ}$, and the high-position holes and low-position holes are arranged alternately. The spacing between the high- and low-position holes is 5 $\mathrm{m}$ (the actual drilling spacing is $4.3 \mathrm{~m}$ ), and the final hole position of the high-position hole is away from the top of the working face. $2 \mathrm{~m}$, the final hole of the low-level hole is $9 \mathrm{~m}$ away from the top surface of the working face. Figures 5-7 show the layout of the working drainage hole in the lower section of the mining section E1085.

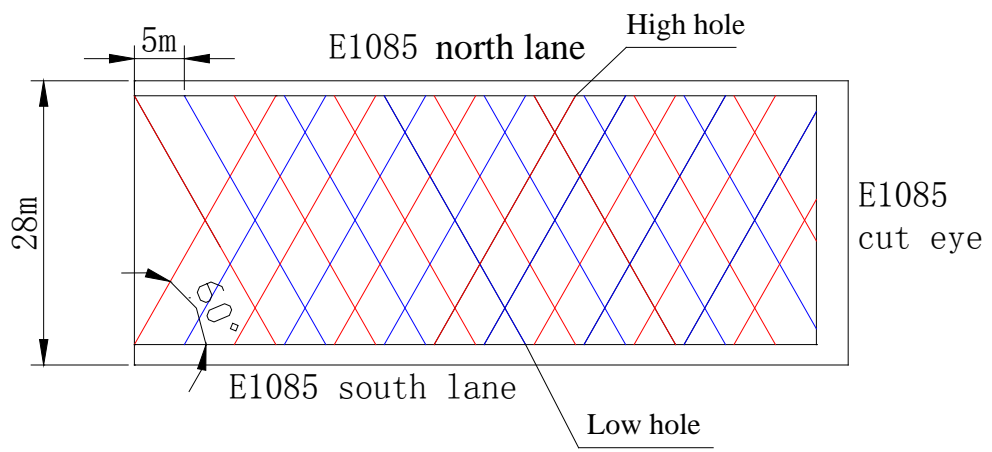

Figure 5. Schematic diagram of the layout of the working face extraction bore.

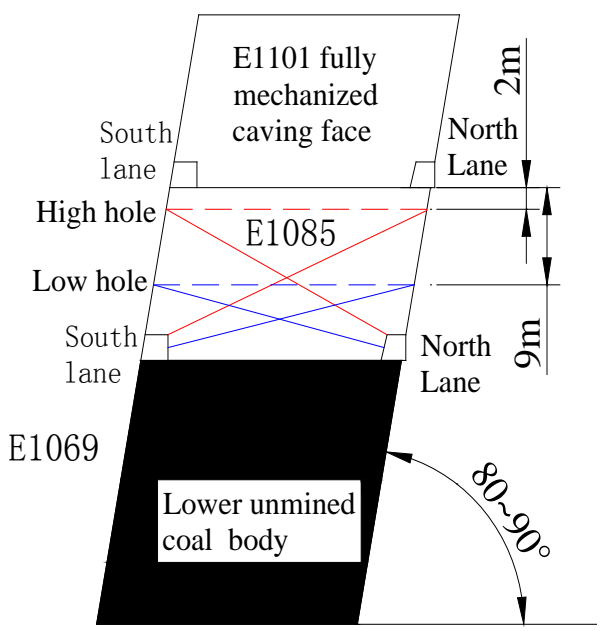

Figure 6. Schematic diagram of the section of the drainage borehole along the coal seam incline. 


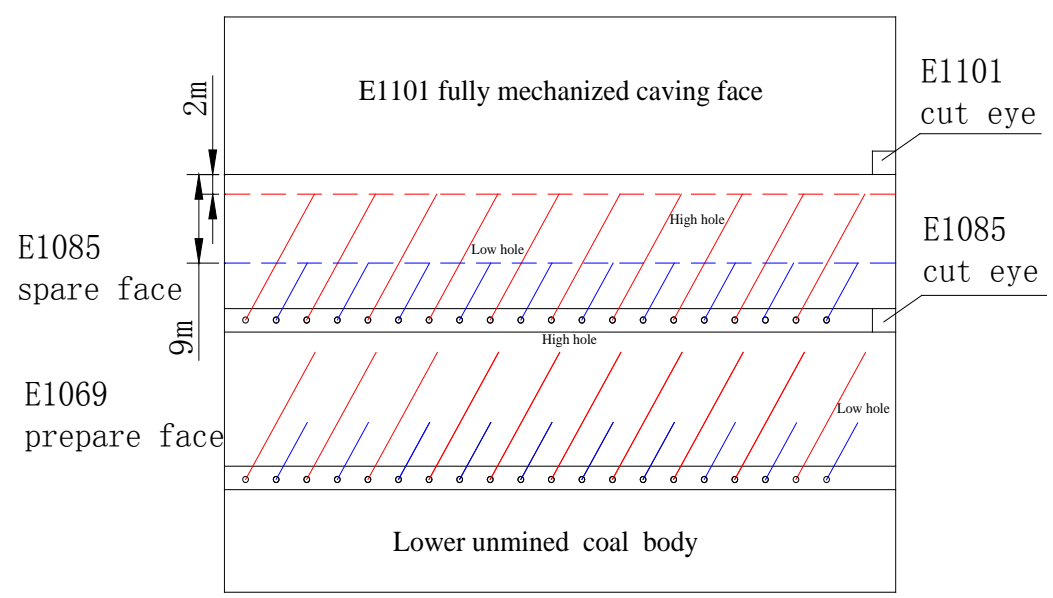

Figure 7. Schematic diagram of the section of the drainage borehole along the strike of the coal seam.

According to the E1085 working face parameters, the intersection of the south and north lane high-level boreholes at the cross section of the working face is about $9.5 \mathrm{~m}$ away from the top face of the working face. The above hole layout parameters meet the requirements of the drainage borehole layout in the upper section after the lower section unloading. Within the middle and lower part of the nip. Due to the large section thickness, the intersection of the low drilling holes is about $13 \mathrm{~m}$ away from the top surface of the working face, which is located in the lower part of the pressure relief zone. Its main function is to strengthen the pre-mining pre-drainage of the coal body gas in the section and reduce the cost of mining in the lower section. The amount of gas emission from the coal body by section. In the same way, before the mining at the E1085 working face, the lower section E1069 working face is prepared for the construction of high and low drainage drilling holes in the roadway, as shown in Figure 7. After the tunnel excavation of the working face is completed, the construction of the drainage drilling will begin, and the holes will be sealed with cement mortar and connected to the pre-drainage system in time for pre-draining.

\section{Effect Analysis of Extraction}

During the recovery of the E1101 working face, the extraction parameters of the high and low drainage holes at the E1085 working face before and after the drilling holes were measured to analyze and verify the rationality of the drilling layout. Through the statistical comparison of the gas emission during the stoping period of the E1101 and E1085 working faces, the gas control effect of the upper-segment fully mechanized caving mining face is analyzed by the arrangement of the lower subsection drainage holes in advance. During the recovery of the E1101 working face, field investigation was carried out on the single hole drainage parameters of the high and low drilling holes in the lower E1085 working face. The relationship between the average gas drainage volume of the high and low drilling holes and the mutual position of the working face is shown in 


\section{Figure 8 .}

It can be seen from Figure 8 that the drainage volume of the drainage borehole is greatly affected by the mining of the upper section E1101 working face. Due to the upper section mining activity, the lower section coal body is away from the upper section working face to a certain extent Stress concentration occurs and when the work faces the position near the end of the borehole, the coal body shrinks and deforms, the air permeability of the coal seam is reduced, the gas flow of the coal seam is blocked, and the drainage volume is reduced. After the working face has passed the position of the final hole of the borehole, due to the influence of mining, the upper coal body stress on the E1085 working face is released, the air permeability of the coal seam increases, the gas flow of the coal seam increases, and the drainage volume increases. It can be seen from Figure 8 that the drainage effect of low-level boreholes is generally lower than that of high-level boreholes, which also shows that the hole layout of low-level boreholes is relatively less affected by upper-stage mining, which confirms that the simulation analysis is in line with the actual situation.

According to the ventilation gas data of the E1101 working face and the E1085 working face during the mining period, the maximum gas concentration of the return air at the E1101 working face is $0.68 \%$, the average gas concentration is $0.46 \%$, the maximum air exhaust gas volume is $7.48 \mathrm{~m}^{3} / \mathrm{min}$, and the average air exhaust gas volume is $4.89 \mathrm{~m}^{3} / \mathrm{min}$. Compared with the upper section E1117 working face, the phenomenon of over-limit gas in the working face is eliminated, the air exhaust gas volume is reduced by about $3 \mathrm{~m}^{3} / \mathrm{min}$ on average, and the gas control effect in the working face is significant. The maximum gas concentration of return air from E1085 working face is $0.54 \%$, the average gas concentration is $0.36 \%$, the maximum air exhaust gas volume is $5.4 \mathrm{~m}^{3} / \mathrm{min}$, and the average air exhaust gas volume is $3.6 \mathrm{~m}^{3} / \mathrm{min}$.

Figure 9 shows the relationship curve of the change of air exhaust gas volume with the advancement of the working face during the stoping period of E1101 and E1085 working face.

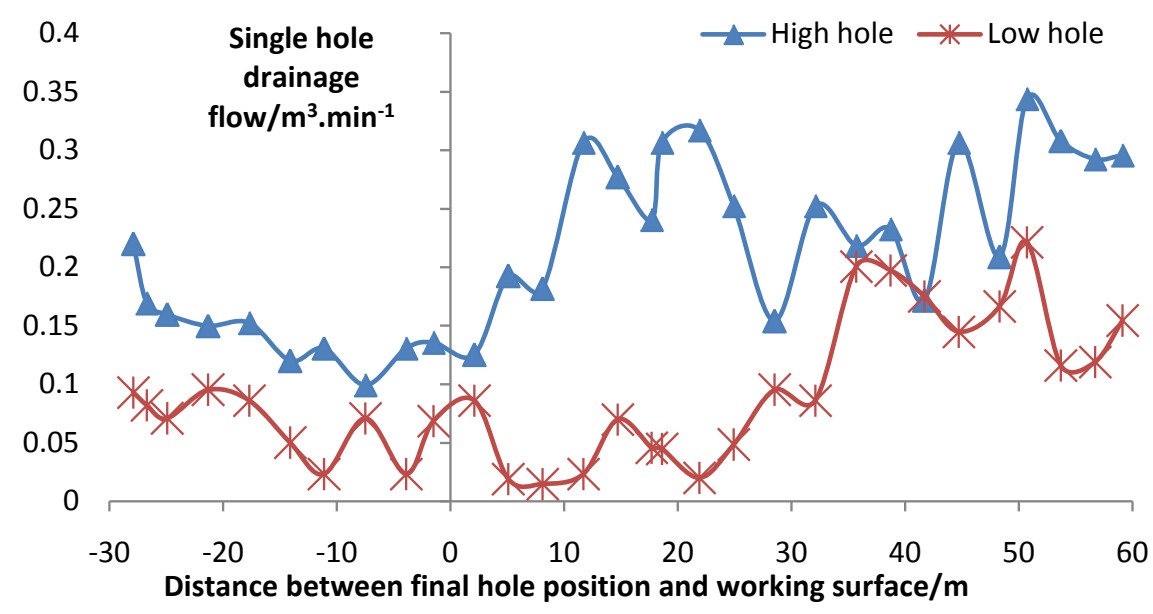

Figure 8. Change curve diagram of drainage scalar volume and working face position. 


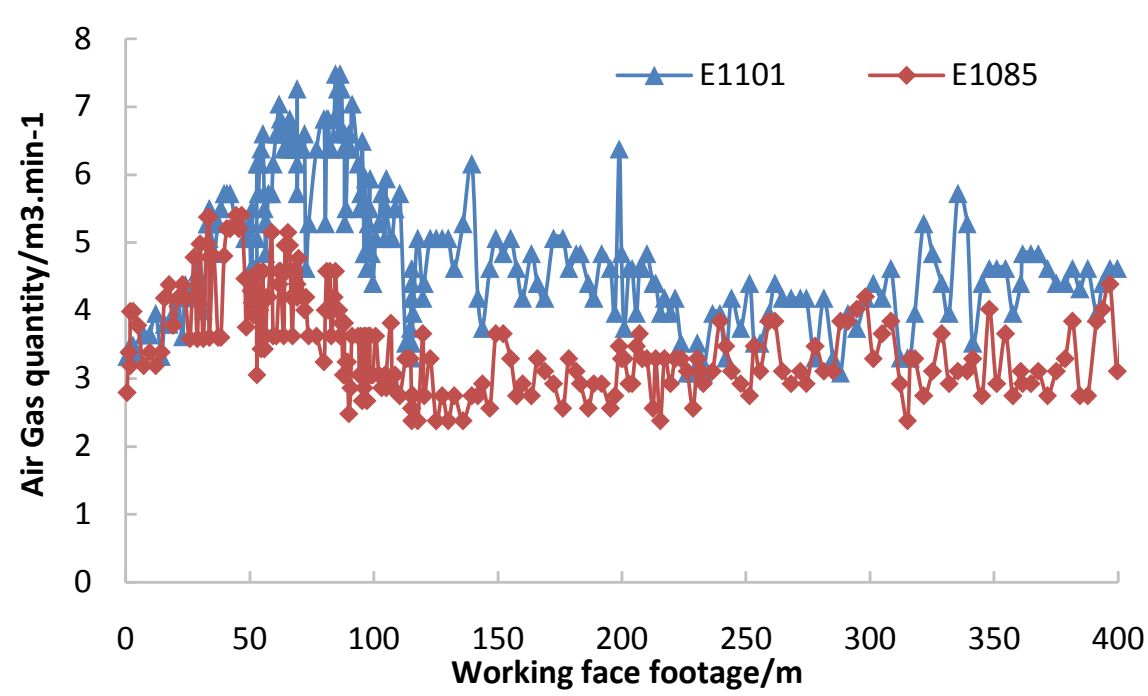

Figure 9. Curve Diagram of gas quantity change with advancing of working face.

It can be seen from Figure 9 that during the stoping period of the E1101 working face, due to the drainage of the high and low boreholes in the lower section E1085 working face, the gas emission of the working face is greatly reduced compared with the upper section E1117 working face. E1085 working face high-position drilling intercepts most of the pressure relief gas in the E1085 working face coal body that flows into the stope space of E1101 working face due to the influence of mining after the upper E1101 working face is mined, and reduces the gas emission of E1101 working face It relieves the pressure of safe gas management at the E1101 working face. Similarly, during the recovery of the E1085 working face, the drainage boreholes of the E1069 working face of the lower section also intercepted the pressure relief gas from the lower coal body. It can be seen from Figure 9 that the air exhaust gas volume of the E1085 working face has been significantly reduced compared with the E1101 working face, and the air exhaust gas volume of the working face is further reduced by $1 \mathrm{~m}^{3} / \mathrm{min}$ on average, which further relieves the pressure of the air exhaust gas of the working face. When the output of the working face is basically the same and the gas content is slightly increased, the amount of gas exhausted by the working face has been significantly reduced. The main reason is that the coal seam gas has been fully pre-drained before the working face. The pre-draining effect of the borehole is distributed. It can be shown that the drainage effect of high and low working face is good, and the drilling layout is reasonable. Therefore, it is reasonable and necessary to arrange high and low drilling holes on the working face as the section work faces deep.

\section{Conclusions}

Through the analysis of the gas source of the sublevel fully mechanized caving mining face in the steeply inclined and extra-thick coal seam of the Adaohai Coal Mine, the numerical simulation of the influence of the upper section min- 
ing on the pressure relief deformation of the lower section coal body, and the layout and drainage of the working face, the effect inspection can draw the following conclusions:

1) The gas emission from the sublevel caving face is mainly from the coal body below the sublevel caving face. The gas emission from the sublevel caving face is the key to solve the problem effectively.

2) After the upper slicing mining, the mining pressure relief range is irregular ellipse arc, that is, the depth of the middle floor is about $10 \mathrm{~m}$, the range of the two sides is $3-4 \mathrm{~m}$. The optimum position of the final hole should be located in $2-3 \mathrm{~m}$ from the upper floor and $8-11 \mathrm{~m}$ from the middle of the working face. Due to the large horizontal sectional thickness, in order to effectively solve the gas emission in the lower sectional working face, the high and low position drilling holes should be arranged in the working face, and the high position drilling holes should be located about 2 meters from the top face, the high position drilling hole is about $9 \mathrm{~m}$ from the working face top surface.

3) Through on-the-spot investigation and data statistical analysis, high and low level drainage boreholes are arranged ahead of time in the lower section of the mining section, which can effectively intercept the relief gas in the lower section of the upper section when mining, the amount of air and gas discharged from the upper sublevel working face is greatly reduced, and the amount of air and gas discharged from the working face is obviously reduced when the coal body gas is fully extracted in the lower sublevel mining, the pressure of air and gas discharge in the working face is further relieved. By pre-pumping high and low level boreholes and cutting off pressure drainage in advance, the gas control of fully mechanized sublevel caving mining face in steep and extra-thick coal seam is realized in a virtuous circle, which provides reliable security for the safe mining of working face.

\section{Conflicts of Interest}

The author declares no conflicts of interest regarding the publication of this paper.

\section{References}

[1] Xu, Y.Q. (1999) Coal Mining. China University of Mining and Technology Press, Xuzhou, 162-166.

[2] Wu, X.J. (2013) Popularization of Mining Technology for Steeply Inclined Thick Coal Seams in Xinjiang. China Energy News, No. 6, 16.

[3] Zhangm D.S., Liu, H.L., Fan, G.W., et al. (2015) Connotation and Prospect of Scientific Mining in Xinjiang Large Coal Base. Journal of Mining and Safety Engineering, 32, 1-6.

[4] Ma, H.T. (2017) A Complete Set of High-Efficiency Gas Drainage Technology for High Gas, Steeply Inclined and Extra-Thick Coal Seams. Mining Safety and Environmental Protection, 44, 53-57.

[5] Ma, P. (2013) Research on Gas Migration Law of Steep Coal Seam in Fully Mecha- 
nized Caving Mining. Xi'an University of Science and Technology, Xi'an.

[6] Fu, Y.S. (2009) Distribution Law of Gas Content in Steep and Extra-Thick Coal Seams. Coal Mine Safety, ZK, 73-75.

[7] Zhang, T.G. (2003) Comprehensive Management Technology of Mine Gas. Coal Industry Press, Beijing.

[8] Zhou, W.Y., Rao, Y.Z., Wang, H., et al. (2014) Research on Numerical Simulation of Stope Stability Based on FLAC3D. Mining Research and Development, 34, 13-17.

[9] He, Q. (2016) Prediction and Development Trend of Gas Emission from Working Face. Mining Safety and Environmental Protection, 43, 98-101.

[10] Liu, Y. (2017) Research on the Prediction Method of Gas Emission in Yangquan Mining Area. North University of China, Taiyuan.

[11] Dai, H.Y., Guo, J.T., Yi, S.H., et al. (2013) Horizontal Slicing Mining of Extremely Thick and Steep Coal Seams and the Mechanism of Surface Movement. Journal of China Coal Society, 38, 1109-1114. 